Original Research Article

\title{
A study of patterns of adverse drug reactions in a tertiary care hospital of Andhra Pradesh, India
}

\author{
Sondi Vinutha, Kuna Kamala*, Nethala Suresh
}

Department of Pharmacology, Andhra Medical College, Visakhapatnam, Andhra Pradesh, India

Received: 06 April 2019 Accepted: 13 April 2019

*Correspondence to:

Dr. Kuna Kamala,

Email: doctorkunas@ yahoo.co.in

Copyright: (C) the author(s), publisher and licensee Medip Academy. This is an openaccess article distributed under the terms of the Creative Commons Attribution NonCommercial License, which permits unrestricted noncommercial use, distribution, and reproduction in any medium, provided the original work is properly cited.

\begin{abstract}
Background: Pharmacovigilance Programme of India (PVPI) is a step towards participation in WHO programme for International Drug Safety Monitoring. Pharmacovigilance (PV) system is an integral part of drug therapy, which helps in detection, monitoring and designing strategies to minimize the occurrence of Adverse Drug Reaction (ADRs). The present study is done to study the patterns of ADRs in a tertiary care government hospital.

Methods: A total of 327 suspected ADR reports submitted to the pharmacovigilance unit at department of pharmacology under PVPI were evaluated for a period of two years with respect to age, sex, causative drug, organ system involvement and seriousness of ADRs. The causality assessment was done using WHO assessment method.

Results: Female patients experienced more (54.13\%) ADRs. The highest percentage (49.24\%) of ADRs were seen in age group of 18-44 years, followed by $45-60$ years $(33.33 \%)$. Medicine department reported the maximum number (42.20\%) of ADRs. Antimicrobial agents (27.83\%) were the commonest group of drugs causing ADRs, followed by anti psychotics (15.90\%) and analgesic drugs $(10.70 \%)$. Skin is the major organ system affected $(30.28 \%)$. Causality assessment revealed (51.99\%) of the ADRs were possible. Majority of the ADRs $(79.82 \%)$ were nonserious and $(20.18 \%)$ were serious requiring hospitalization. Death occurred in five patients.

Conclusions: The results suggest that there is under reporting and there is a need to create awareness among health care professionals(HCP) about the importance of Pharmacovigilance. The data also helps in designing strategies for framing policies towards safer use of drugs in future.
\end{abstract}

Keywords: Adverse drug reactions, Anti microbial agents, Causality assessment, Pharmacovigilance

\section{INTRODUCTION}

The WHO defines an adverse drug reaction(ADR) as "a response to a drug which is noxious and unintended and which occurs at doses normally used in man for prophylaxis ,diagnosis, or therapy of disease or for the modifications of physiologic function." ADRs represent a significant public health problem but they are sometimes preventable .Around 5\% of all hospital admissions are the result of an ADR and around $10 \%-20 \%$ of inpatients will have at least one ADR during their hospital stay. ${ }^{2-4}$ Strategies targeting towards ADR monitoring and reporting can help in alleviating these harmful effects. The history of ADR monitoring dates back to 1960s. In 1963, 'The Sixteenth World Health Assembly' adopted a resolution that reiterated the need for monitoring and propagating ADR information. ${ }^{5}$ In 1968, the International Drug Monitoring Program was started initially as a pilot project in 10 countries, the network has since expanded significantly and currently most of the advanced countries have set up an adverse drug reaction reporting system at the national level. The Program is coordinated by WHO, with its collaborating centre in Uppsala, Sweden. ${ }^{6}$ The rapid induction of pharmaceutical products throws up the challenges of monitoring Adverse Drug Reactions (ADRs) in a vast country like India with a population of over 1.2 billion with ethnic variability, practice of different systems 
of medicines. ${ }^{7}$ In 1997, India joined the WHO Program for International Drug Monitoring and the National Pharmacovigilance program was launched in November 2004. However, in the mid 2009 the program was temporarily suspended. Recognizing the need Central Drugs Standard Control Organization (CDSCO), Directorate General of Health Services under the aegis of Ministry of Health and Family Welfare, Government of India in collaboration with Indian Pharmacopeia commission, initiated the new Pharmacovigilance Program of India (PvPI) in July 2010 with the goal, that the benefits of use of medicine should outweigh the risks. ${ }^{8}$ It is essential to have constant surveillance, collection and analysis of the data regarding drugs (including the incidence, type of adverse event, severity) in a systematic manner for assessing the safety of drugs in a hospital setting. The data derived from within the country may be helpful for national regulatory body in decision-making and may have educational value. ${ }^{9}$ Thus, the present study was done to monitor and study the patterns of ADRs in Inpatients and outpatients of different departments of a tertiary care government hospital.

\section{METHODS}

This prospective observational study was done in the Department of Pharmacology at Andhra Medical College which is associated with King George Hospital, Visakhapatnam, Andhra Pradesh, India, for a period of two-years from 2016-2018. The Department of Pharmacology, Andhra Medical College is the regional ADR Monitoring Center for Visakhapatnam under PvPI, which is a government teaching hospital, providing health facilities. The reports are collected from both inpatient and outpatient departments of hospital for suspected ADRs. Data is collected using structured format as per CDSCO ADR reporting form. ${ }^{9}$ Causality assessment is performed using WHO Uppsala Monitoring Centre (UMC) Global introspection method. The reports are then uploaded in Vigiflow software and sent to National Coordinating Centre, Indian Pharmacopoeia Commission, Ghaziabad, which then transmits the reports to the Uppsala Monitoring Center's ADR database where signal processing is carried out. Suspected adverse drug reaction reports due to medications submitted to the Department of Pharmacology, Andhra Medical College, Visakhapatnam, Andhra Pradesh under the Pharmacovigilance Program of India in the last 2 years (January 2016- December 2018) were included. Incomplete forms with respect to the patient's information, medication details, and inadequate description of the events were excluded from the analysis. ADRs pertaining to patients using medication of alternative system of medicines, mentally retarded patients, drug addicts, drug over dosage, excess consumption, were also excluded from the analysis.

The 327 suspected ADR reports received by Pharmacovigilance unit at the Department of Pharmacology between January 2016 and December 2018. The reports acquiesced were analyzed for patient profile (age, sex), patients medication details (generic name of the medicine, dose frequency, strength, date of start and stop) description of the adverse event, onset and ablation of adverse event, information on de-challenge, rechallenge and causality assessment. Causality assessment was done using WHO assessment Scale10. Reports were also categorized as serious and non-serious. ${ }^{9}$ Any ADR which was fatal, life-threatening, permanently/significantly disabling, required initial hospitalization or prolonged hospitalization, caused a congenital anomaly, required intervention to prevent permanent impairment or damage was labeled as serious ADR. ${ }^{9}$

\section{Statistical analysis}

Data were entered in Microsoft Excel 2016. Descriptive analysis was done to assess mean \pm standard error of mean, median, frequencies and the percentages as applicable for age group, gender, causative drug, seriousness, severity, and causality.

\section{RESULTS}

A total of 327 ADRs were received. There was predominance of female patients 177 (54.13\%) as compared to males 150 (45.87\%) (Figure 1).

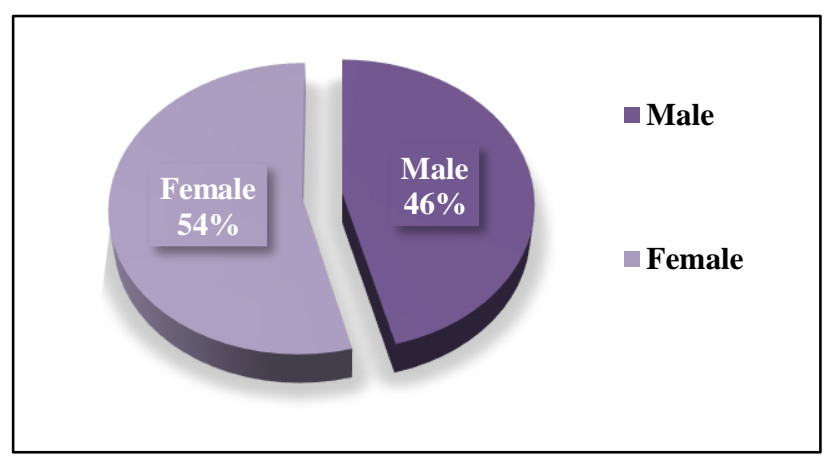

Figure 1: Gender distribution of adverse drug reactions.

Table 1: Age distribution.

\begin{tabular}{|lll|}
\hline $\begin{array}{l}\text { Age group (in } \\
\text { years) }\end{array}$ & $\begin{array}{l}\text { No of Patients } \\
\text { with ADR's }\end{array}$ & Percentage (\%) \\
\hline$<3$ & 6 & $1.84 \%$ \\
\hline $3-17$ & 15 & $4.59 \%$ \\
\hline $18-44$ & 161 & $49.24 \%$ \\
\hline $45-60$ & 109 & $33.33 \%$ \\
\hline$>60$ & 36 & $11.00 \%$ \\
\hline Total & 327 & $100 \%$ \\
\hline
\end{tabular}

Mean age of the patients was $31.472 \pm 15.499$ years (Standard Devation) with maximum number of patients in the age group of $18-44$ years $(49.24 \%)$. The maximum number of ADRs were observed in age group of 18-44 years $(49.24 \%)$, followed by $45-60$ years $(33.33 \%)$. The least number of patients are seen in the age group of below 
three years $6(1.84 \%)$. Between 3-17 years patients are 15 $(4.59 \%)$. Total 36 patients $(11.00 \%)$ are above the age of 60 years (Table 1$)$.

Table 2: Distribution of ADRs in various departments.

\begin{tabular}{|ll|}
\hline Name of department & $\begin{array}{l}\text { Total no of patients with } \\
\text { ADR's }\end{array}$ \\
\hline Medicine & 138 \\
\hline Psychiatry & 67 \\
\hline Surgery & 35 \\
\hline Endocrinology & 29 \\
\hline Dermatology & 26 \\
\hline Oncology & 26 \\
\hline Pediatrics & 5 \\
\hline OBG & 1 \\
\hline
\end{tabular}

The maximum number of ADRs were reported from the department of medicine 138 (42.20\%), followed by psychiatry 67 (20.49\%), surgery $35 \quad(10.70 \%)$, endocrinology 29 (8.86\%), dermatology $26 \quad(8 \%)$, oncology $26(8 \%)$, paediatrics $5(1.53 \%)$ and OBG1 $(0.30 \%)$ (Table 2).

Table 3: Systems affected by ADRs.

\begin{tabular}{|lll|}
\hline $\begin{array}{l}\text { Systems Affected by } \\
\text { ADR }\end{array}$ & No. of ADR & $\begin{array}{l}\text { Percentage } \\
(\%)\end{array}$ \\
\hline Dermatology & 99 & 30.28 \\
\hline $\begin{array}{l}\text { Central nervous } \\
\text { system }\end{array}$ & 62 & 18.96 \\
\hline $\begin{array}{l}\text { Gastrointestinal } \\
\text { system }\end{array}$ & 54 & 16.51 \\
\hline General & 52 & 15.90 \\
\hline $\begin{array}{l}\text { Cardio vascular } \\
\text { system }\end{array}$ & 26 & 7.95 \\
\hline Respiratory & 18 & 5.51 \\
\hline Endocrine & 16 & 4.89 \\
\hline
\end{tabular}

The skin is the most affected organ $(30.28 \%)$ followed by central nervous system $(18.96 \%)$, gastrointestinal system (16.51\%), general illness $(15.90 \%)$, cardiovascular system $(7.95 \%)$ respiratory $(5.51 \%)$, endocrine $(4.89 \%)$ systems respectively. The frequently observed types of ADRs were rashes $(14.37 \%)$, tremors $(6.12 \%)$, gastritis $(5.5 \%)$, chills and rigors $(5.20 \%)$, nausea and vomiting $(3.36 \%)$, dry cough $(3.36 \%)$. The other ADRs that were observed included hyperglycemia, insomnia, alopecia, hearing loss, decreased libido, dyspnoea, hepatitis, sedation, lethargy, sexual dysfunction, body ache, febrile neutropenia and Redman syndrome, Steven Johnson syndrome (Table 3).

The leading causal therapeutic class of medicines implicated were antimicrobials $(27.83 \%)$ followed by antipsychotics $(15.9 \%)$, analgesics $(10.7 \%)$, anticancer drugs $(7.95 \%)$, anti epileptic drugs $(7.03 \%)$, anti diabetic drugs $(6.73 \%)$, anti hypertensives drugs $(5.81 \%)$ (Table 4$)$. Among the antimicrobial agents (AMAs), ceftriaxone $(31.07 \%)$ was the most common suspected AMA causing
ADRs. Other medicines which were associated with ADRs included docetaxel, cisplatin, olanzapine, risperidone, diclofenac etc. $(6.73 \%)$ are other drug category which include fluids like ringer lactate , hair dye, MRI contrast dye gadodiamide, betadine, disulfiram, Nootropics like cerebrolysin and vitamins.

Table 4: Class of suspected drugs.

\begin{tabular}{|lll|}
$\begin{array}{l}\text { Drugs most frequently } \\
\text { implicated in causing } \\
\text { ADRs }\end{array}$ & $\begin{array}{l}\text { No. of } \\
\text { ADRs }\end{array}$ & $\begin{array}{l}\text { Percentage } \\
(\%)\end{array}$ \\
\hline Anti microbial drugs & 91 & $27.83 \%$ \\
\hline Anti psychotic drugs & 52 & $15.90 \%$ \\
\hline Analgesics & 35 & $10.70 \%$ \\
\hline Anti cancer & 26 & $7.95 \%$ \\
\hline Anti epileptic drugs & 23 & $7.03 \%$ \\
\hline Anti diabetic drugs & 22 & $6.73 \%$ \\
\hline Anti hypertensives & 19 & $5.81 \%$ \\
\hline Anti platelet drugs & 7 & $2.14 \%$ \\
\hline Anti ulcer drugs & 6 & $1.83 \%$ \\
\hline Anti hyperlipidemic drugs & 6 & $1.83 \%$ \\
\hline Anti coagulant drugs & 4 & $1.22 \%$ \\
\hline Anti histaminics & 3 & $0.92 \%$ \\
\hline Anti depressant drugs & 2 & $0.61 \%$ \\
\hline Anti diuretic drugs & 2 & $0.61 \%$ \\
\hline Anti emetic drugs & 2 & $0.61 \%$ \\
\hline Corticosteroids & 2 & $0.61 \%$ \\
\hline Anti anxiety & 1 & $0.31 \%$ \\
\hline Anti obesity drugs & 1 & $0.31 \%$ \\
\hline Drugs in heart failure & 1 & $0.31 \%$ \\
\hline Other drugs & 22 & $6.73 \%$ \\
\hline
\end{tabular}

Majority of the ADRs were non-serious (79.82\%) and $(20.18 \%)$ were serious and required hospitalization (Figure 2). The serious included Steven Johnson syndrome, toxic epidermal necrolysis, fixed drug eruption, acute anaphylaxis, vasculitis, hypoglycaemia. Death occurred in five patients with ceftriaxone induced severe anaphylaxis.

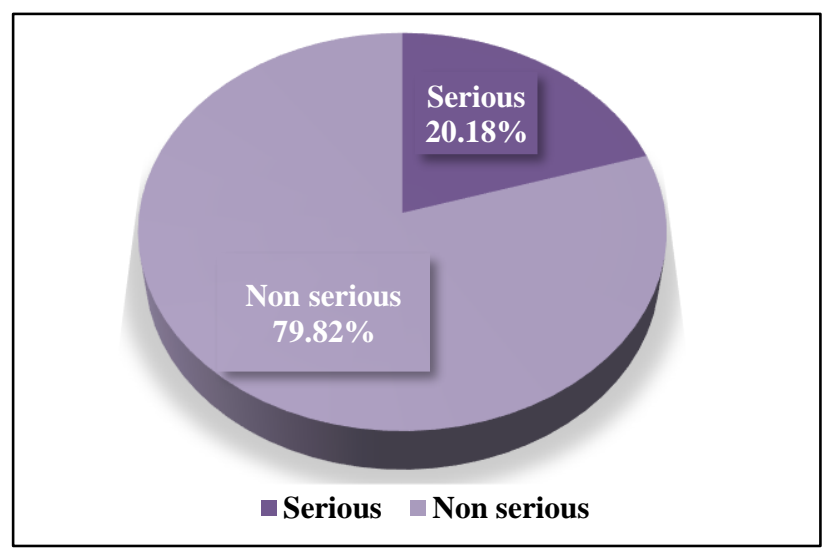

Figure 2: Seriousness of adverse drug reaction.

On causality assessment using WHO-UMC assessment scale $(51.99 \%)$ ADRs were categorized as possible, 
$(47.1 \%)$ were categorized as probable and $(0.91 \%)$ were categorized as certain. The other assessment criteria of unlikely, unclassified and unclassifiable as per WHOUMC assessment scale are $0 \%$ (Table 5).

Table 5: WHO-UMC causality assessment scale.

\begin{tabular}{|ll|}
\hline Causality term & $(\%)$ of ADR \\
\hline Possible & 51.988 \\
\hline Probable & 47.095 \\
\hline Certain & 0.917 \\
\hline
\end{tabular}

\section{DISCUSSION}

The foremost bases of ADR data are spontaneous reporting by healthcare professionals, clinical trials, vital statistics (birth registers for congenital defects) and special studies (case control studies, cohort studies). ${ }^{11}$ ADR reporting adds to increased vigilance and influence recommendations of drug use. ${ }^{12}$ In the present study the reporting sources were doctors (consultants, senior residents, junior residents, interns) and nurses. The demographic details of the present study showed female gender predominance over males for ADRs, this finding is similar to that of other studies reported in the literature. ${ }^{13-16}$ Women experience adverse reactions more frequently than men do. ${ }^{13,17}$ This finding may be because women and men show different pharmacokinetic and pharmacodynamic responses to drugs. Pharmacokinetic differences arise because of differences in body weight, body mass index, fat composition and liver metabolism. Hormonal changes during puberty, menstruation, menopause and the genomic constitutional differences may also influence the levels of various drug metabolizing enzymes in females. ${ }^{18}$ These differences can ultimately influence dosing of drugs with narrow therapeutic index. In addition to this woman take more medications than men and are more likely to experience an adverse event due to drug-drug interactions. ${ }^{13}$ Other factor which may predispose to ADRs in general, is the genetic constitution e.g. the HLA type may predispose to reactions to drugs like aspirin and slow $\mathrm{N}$-acetylation phenotype may predispose to sulphonamide reactions.

In the present study, a higher percentage of ADRs occurred in adult population (18-44 years), the mean age being $>31$ years which is similar to that reported by the other studies. ${ }^{16,19,20}$ Adverse drug reactions have been reported to occur mainly in young and middle aged adults. ${ }^{14}$ Reason could be that the patients of this age group are more prone to diseases, are often on multiple drug therapy and frequently visits the outpatient department for their regular check-ups. ${ }^{20}$

The organ system most often affected by ADRs in our study was skin followed by gastrointestinal system and the central nervous system. This finding is consistent with many studies which have reported a higher percentage of dermatological manifestations than others. ${ }^{16,21-23}$ Drug induced rashes are the commonest adverse reaction of many drugs. Possible explanation may be that as these ADRs are visible they are readily detected, further education in regard to detection of ADRs using symptoms and laboratory values is necessary. Usually the mechanisms of such drug induced reactions are unknown and only $10 \%$ of these results from true allergic mechanisms. $^{14}$

The most frequently implicated group of medicines in the ADRs was antimicrobial agents, this finding is consistent with other studies. ${ }^{21,24}$ Amongst the antimicrobial agents ceftriaxone accounted for the highest number of the ADR reports. Similar to the present study other studies have also shown that Beta lactam antibiotics (amoxicillin, ceftriaxone) are the most common drugs associated with ADRs. ${ }^{11,22}$

The majority of reactions were non-serious 261 (79.82\%) and 66 reactions (20.18\%) were serious. Most of the ADRs reported were mild and thus were managed by withdrawing the offending drug and by providing the symptomatic treatment to manage the ADRs, as done in few other studies. ${ }^{25,26}$ In severe cases hospitalization was done and most of them recovered, however, five ADRs were fatal.

The causality assessment revealed that most of the ADRs belonged to "possible" followed by "probable" category, this is consistent with that reported by other studies. ${ }^{27,28}$

The major limitation of the study is that it was based on spontaneous reporting system which precludes calculation of incidence and prevalence related to specific ADRs. However, it has provided the base line data about the pattern of ADRs at our hospital, which can be used in framing policies towards rational use of drugs.

The present work also showed that there is under reporting in this institution. A closer liaison between the health care professionals and pharmacovigilance centre ,periodic reinforcement of the health care professionals regarding pharmacovigilance can further improve spontaneous reporting.

\section{CONCLUSION}

The monitoring and reporting of suspected ADRs by health care professionals aids in improved patient welfare. This also acts as an alerting mechanism for physicians. In authors opinion facilitating an easy contact and quick access to the hospital pharmacovigilance system through telephone, drop boxes, fax, internet and periodic feedback about the pharmacovigilance activities, can ultimately result in increased incidence of reporting. However, robust methodology is required for implementation of these strategies into the hospital healthcare system to reduce the impact of adverse drug reaction.

Funding: No funding sources Conflict of interest: None declared

Ethical approval: Not required 


\section{REFERENCES}

1. Safety Monitoring of Medicinal Products: Guidelines for setting up and running a Pharmacovigilance Center. Uppsala Monitoring Center - WHO Collaborating center for international drug monitoring, EQUUS, London, 2000. Available at: http://apps.who.int/medicinedocs/en/d/Js4893e/9.htm 1 .

2. Kongkaew C, Noyce PR, Ashcroft DM. Hospital admissions associated with adverse drug reactions: a systematic review of prospective observational studies. Ann Pharmacother. 2008;42(7-8):1017-25.

3. Lundkvist J, Jönsson B. Pharmacoeconomics of adverse drug reactions. Fundam Clin Pharmacol. 2004;18(3):275-80.

4. Pirmohamed M, Breckenridge AM, Kitteringham NR, Park BK. Adverse drug reactions. BMJ. 1998;316(7140):1295-8.

5. The pharmacovigilance news - National Drug Authority. Available at: www.nda.or.ug/docs/bulletin\%20issue\%20No.1.pdf. Accessed 29 September 2012.

6. Pharmacovigilance: ensuring the safe use of medicines. Available at: whqlibdoc.who.int/hq/2004/WHO_EDM_2004.8.pdf. Accessed 29 September 2012.

7. Pharmacovigilance Programme of India. Available at: http://cdsco.nic.in/pharmacovigilance_intro.htm.

8. Gupta YK. Ensuring patient safety-launching the new pharmacovigilance programme of India. Pharma Times. 2010;42(8):21-6.

9. Safety of Medicines. Available at: whqlibdoc.who.int/hq/2002/WHO_EDM_QSM_200 2.2.pdf. Accessed 27 April 2012.

10. WHO-UMC Causality Assessment System. Available at: http://www.who-umc.org/pdfs/Causality.pdf. Cited July 2014. Accessed 29 February 2015.

11. Palanisamy S, Arul Kumaran KS, Rajasekaran A. A study on assessment, monitoring, documentation and reporting of adverse drug reactions at a multi-specialty tertiary care teaching hospital in South India. Int $\mathbf{J}$ PharmTech Res. 2009;1:1519-22.

12. Gor AP, Desai SV. Adverse drug reactions (ADR) in the inpatients of medicine department of a rural tertiary care teaching hospital and influence of pharmacovigilance in reporting ADR. Indian $\mathbf{J}$ Pharmacol. 2008;40(1):37.
13. Margaret Ann Miller. Gender-Based Differences in the Toxicity of Pharmaceuticals-The Food and Drug Administration's Perspective. Int $\mathrm{J}$ Toxicol. 2001;20:149-52.

14. Vervloet D, Durham S. ABC of allergies adverse reaction to drugs. BMJ. 1998;316:1511-4.

15. Singh H, Dulhani N, Kumar BN, Singh P, Tewari P, Nayak K. A Pharmacovigilance Study in Medicine Department of Tertiary Care Hospital in Chhattisgarh (Jagdalpur). J Young Pharm. 2010;2(1):95-100.

16. Jha N, Bajracharya O, Namgyal T. Prevalence of adverse drug reactions with commonly prescribed drugs in different hospitals of Kathmandu valley. Kathmandu Univ Med J. 2007;5(4):504-10.

17. Kando JC, Yonkers KA, Cole JO. Gender as a risk factor for adverse events to medications. Drugs. 1995;50(1):1-6.

18. Harris RZ, Benet LZ, Schwartz JB. Gender effects in pharmacokinetics and pharmacodynamics. Drugs. 1995;50(2):222-39.

19. Agouzal M, Benkirane R, Soulaymani A, Benjelloun R, Soulaymani-Bencheikh R, Quyou A. Prevalence of adverse drug events in the consultation centre of Ibn Sina. Afr J Pharma Pharmacol. 2009;3(9):449-53.

20. Sharma H, Aqil M, Imam F, Alam MS, Kapur P, Pillai KK. A pharmacovigilance study in the department of medicine of a university teaching hospital. Pharma Pract. 2007 Mar;5(1):46-9.

21. Palaian S, Ibrahim MI, Mishra P. Pattern of adverse drug reactions reported by the community pharmacists in Nepal. Pharma Pract. 2010;8(3):201.

22. Baniasadi S, Fahimi F, Shalviri G. Developing an Adverse Drug Reaction Reporting System at a Teaching Hospital. Basic Clin Pharmacol Toxicol. 2008;102(4):408-11.

23. Jose J, Rao PG. Pattern of adverse drug reactions notified by spontaneous reporting in an Indian tertiary care teaching hospital. Pharmacol Res. 2006;54(3):226-33.

Cite this article as: Vinutha S, Kamala K, Suresh N. A study of patterns of adverse drug reactions in a tertiary care hospital of Andhra Pradesh, India. Int J Basic Clin Pharmacol 2019;8:860-4. 